\title{
Pornografi Sebagai Sebuah Realitas Sosial (Kajian dari Aspek Filsafat Sosial dan Agama)
}

\author{
Muhammad Djakfar dan Rasmianto
}

Penulis adalah Dosen Universitas Islam Indonesia Sudan (UIIS) Malang

\begin{abstract}
Pornography and porno-action are the two words commonly heard and often become the community discourse. Even today the porno-action, which exploits the body of human being-especially the women-, become worse and is covered nicely as marketable entertainment business. It is believed that the growth of pornography and porno-action is not caused by a single Variable but is supported by other variables usually done by the artists as public figure and published by mass media.

According to social philosophy paradigm, the great amount of pornography and porno-action today has clearly destroyed the perfect order of social structure. While according to Islam, it depends on how deep the subject's belief to the religious norm is.

The more firmly they hold the religious values, the more slowly pornography and porno-action develop, so that the social structure is not very much disturbed.

Therefore, the instruments to be applied to slow down the development of pornography and porno-action are establishing social awareness, as well as realizing the regulations for anti-pornography which function as efforts of prevention and cure.
\end{abstract}

Ulul Albab, Vol. 4 No. 1, 2003 


\section{Pendahuluan}

Di negeri kita nama Inul Daratista pernah menjadi sorotan dan buah berbincangan di seluruh lapisan masyarakat, mulai masyarakat awam sampai ke tingkat guru besar di kalangan akademik. Kasus Inul bisa dikatakan merupakan puncak, sekaligus ikon maraknya pornografi dan pornoaksi di negeri tercinta ini. Mampu mencapai puncak, sudah barang tentu Inul tidak berdiri sendiri. Ia didukung oleh faktor-faktor yang memungkinkan untuk itu, antara lain media massa, baik cetak maupun elektronik. Media massa-lah yang mengangkat nama Inul naik ke permukaan yang semula hanya berpredikat sebagai penyanyi "kacangan" di daerah asalnya Pasuruan. Dalam waktu yang relatif singkat nama Inul mampu menduduki posisi yang sejajar dengan pedangdut-pedangdut top lainnya sehingga gambar dan suaranya banyak disorot dan diperdengarkan oleh berbagai surat kabar dan televisi.

Kendati hanya bermodal seadanya, menurut Ade Armando, Inul adalah artis yang berani menabrak tabu, yakni berani atau nekad membelakangi penonton sambil memutar-mutar bagian sensitifnya. Sebelum dia, tidak ada artis yang berani melakukan gerakan semacam itu' Karena gerakan-gerakannya yang erotis itulah kemudian muncul julukan spektakuler kepada Inul yaitu sebagai si ratu ngebor. Anehnya, gerakan-gerakan ngebor itu ternyata banyak mengundang perhatian khalayak, bahkan dieksploitasi sebagai komoditas yang layak jual sebagai bisnis hiburan (entertainment) di stasiun-stasiun televisi.

Selain media massa, media teknologi yang turut mengorbitkan popularitas nama Inul adalah VCD. Konon katanya gerakan-gerakan sensualitas Inul yang paling wah justru di lempengan besi ini yangbisa dinikmati segala lapisan masyarakat karena bebas dijual dipasaran dengan harga yang sangat murah.

Namun demikian secara jujur kita katakan, bahwa kasus Inul yang menghebohkan itu hanyalah puncak, dan karena itu ia tidak sendirian dalam menjual sensualitas berbau porno berkedok seni/hiburan. Sebelumnya, aksi-aksi semacam Inul juga sudah dilakukan oleh banyak orang. Lihatlah penari latar (koreografer) yang menyertai panggung-panggung hiburan, di sana dipamerkan pakaian minim disertai berbagai gerakan erotisme. Aurat bukan lagi hal yang tabu, bahkan bisa dikatakan, bagian-bagian yang seharusnya disembunyikan dari para perempuan justru itu yang dijual dan diekspose ${ }^{2}$ Betapa luar biasa dan sungguh aneh akhirakhir ini bagaimana cara pandang pebisnis hiburan di negeri Indonesia tercinta ini. 
Dengan dorongan egoisme kapitalisme yang tinggi mereka tidak lagi mempertimbangkan effek pertunjukan yang mereka jual di tengah publik. Nafsu terbesar mereka adalah memperoleh keuntungan finansial yang secara sadar atau tidak telah mengeksploitasi wilayah-wilayah erotis kaum hawa. Demi uang, mereka memakai katup pengaman dari sebagian pendapat pengamat seni dan budaya yang menyatakan bahwa pertunjukan erotisme adalah hasil dari sebuah kreativitas seni yang tidak perlu dipersoalkan. Hargailah hasil kreativitas mereka dan tidak perlu dipertentangkan dengan nilai-nilai moral, apalagi nilai agama. Nampaknya sebagian pengamat kita berpandangan bahwa seni adalah seni dan bebas nilai. Karenanya, membenturkan hasil sebuah seni dengan nilai moral dan agama, sama halnya dengan upaya pemasungan terhadap sebuah kreativitas.

Dengan adanya tayangan yang jelastidak mendidik dan tidak terpuji itu terlihat jelas kontradiksi antara satu tayangan dengan tayangan yang lain yang dilakukan oleh media audio visual sehingga semakin kabur misi apa yang dibawa oleh masingmasing media massa itu. Katakan saja, setiap pagi masing-masing televisi mengagendakan acara yang bernuansakan spiritual keagamaan dengan nama acara dan narasumber yang beragam. Ambil saja contoh, hikmah pagi, pukul 05.30 (TVRI); hikmah fajar, pukul 05.00 (RCTI); ambang-fajar, pukul 05.00 (SCTV); embun pagi, pukul 05.00 (INDOSIAR); dan kuliah subuh, pukul 05.00 (TPI) ${ }^{3}$ Paket acara spiritual ini seakan menguap begitu saja tanpa bekas karena sebagian besar agenda tayangannya berbau pornografi baik dalam bentuk sinetron maupun iklan.

\section{Tanggapan Para Tokoh}

Dengan melihat realitas sosial seperti di atas, lalu siapakah yang bersalah berkaitan dengan semakin maraknya pornografi dan pornoaksi di negeri ini? Mengapa penertiban masalah ini sulit sekali dilakukan? Nampaknya dalam menyikapi persoalanpelik ini telah terjadi saling lempar tanggungjawab. Para ulama dan orangorang yang merasa bertanggungjawab akan keselamatan moral anak bangsa langsung menuduh media massa. Menurut mereka, media massa-lah yang berperan besar dan turut mengkondusifkan suburnya pornografi dan pornoaksi. Untuk jelasnya, wacana ini mencoba merangkum tanggapan para tokoh sebagai reaksi 
atas perilaku segelintir komunitas yang dianggap mempunyai dampak besar kepada moralitas masyarakat, terutama di kalangan kaum muda ${ }^{4}$

Ketua Umum Persatuan Islam (Persis), KH Shidik Amin menyatakan, para sutradara atau produser film dan pengelola media merupakan motor kian maraknya pornografi dan pornoaksi. "Mereka mengeksploitasi aurat wanita untuk kepentingan bisnis dan mengeruk materi tanpa mempedulikan moral dan nilai agama", katanya. Menurut Kiai Shidik, berbagai tayangan hiburan di televisi sudah sangat parah. Bukan hanya goyang Inul, tapi juga film-film atau sinetron. Yang lebih memprihatinkan, lanjut Shidik, karena pengelola media mempunyai uang dan kuasa, mereka bisa mengatur seenaknya tayangan-tayangan yang menguntungkan. Ia mencontohkan, aksi-aksi penolakan terhadap pornografi sengaja mereka kecilkan, sementara mereka yang membela Inul dibesar-besarkan. Mereka sudah berani melecehkan institusi agama seperti MUI yang memfatwakan pelarangan tayangan Inul:"

Hal senada disampaikan Ketua MUI Pusat KHUmar Shihab. Ia menyatakan, maraknya pornografi dan pornoaksi karena digerakkan oleh kekuatan bermodal besar, terutama pengelola stasiun televisi. "Yang namanya media tentu hanya berorientasikan bisnis dan mencari keuntungan. Akibatnya, moral jadi berantakan," ujarnya. Ia menghimbau agar pengelola media tidak hanya mencari keuntungan, tapi juga harus ada kesadaran untuk ikut membangun akhlak bangsa. "Jangan karena alasan bisnis menghalalkan segala cara. Kita minta, tayangan yang berbau pornografi, pornoaksi, dan erotisme ditertibkan:"

Berbeda dengan Shidik dan Shihab, Sekum PP Muhammadiyah, Haedar Nashir mencatat ada dua faktor utama yang menyebabkan pornografi dan pornoaksi begitu marak. Pertama, kondisi sosial masyarakat mengalami semacam sosiopotik, yakni masyarakat secara sosial makin banyak yang sakit, padahal sebenarnya mereka sehat secara jasmani. Masyarakat demikian menganggap yang sehat adalah sakit. Justru karena itu Nashir tidak heran bila fenomena Inul gencar seperti sekarang ini, kalangan yang mengkritik pun dianggap sakit. Sebaliknya, kalangan yang matimatian membela Inul diklaim sebagai pihak yang sehat. Kedua. Lanjut Haedar, faktor alam pikiran. Alam pikiran masyarakat sudah sedemikian cenderung pada gaya hidup hedonistik dan sekularistik. Orang tak,lagi memikirkan nasib orang lain, tapi hanya mementingkan diri sendiri. Inilah fenomena sekularistik masyarakat kita. 
Sekjen Dewan Dakwah Islamiyah Indonesia (DDII) H Hussein Umar menegaskan, maraknya pornografi dan pomoaksi lebih disebabkan lemahnya kontrol dan sensor. Saat ini katanya, tidak ada yang namanya sensor kepada media massa, terutama media elektronik. "Semua kebudayaan sebisa mungkin dimasyarakatkan oleh media massa, tidak peduli apa dampaknya. Bagi pengelola media massa, yang penting adalah keuntungan." Dampak dari semua itu lanjut, Hussein, sudah sangat tampak. Diantaranya, angka aborsi yang dilakukan wanita Indonesia mencapai tiga juta setiap tahunnya. Sebagian besar dilakukan kaum muda usia. Ini berarti., akhlak dan moral tak ada lagi, akibat pergaulan bebas dan dampak pornografi serta pornoaksi.

Rektor Universitas Islam Asy-Syafiiyah, Jakarta, Dr. Hj Tutik Alawiyah, menyesalkan para pendukung Inul yang ia sebutkan sebagai pendukung pornografi dan pornoaksi. Menurutnya, sangat salah kalau joget Inul dianggap sebagai bagian dari kebebasan berekspresi. Mereka sudah menjadi adalah kaum hedonis: Yang mereka kejar sebenarnya bukan Inul, tapi kapitalisme, keuntungan sebasar-besamya. Inul hanyalah jalan menuju ke sana, kata Alawiyah.

Selanjutnya instrumen apa yang harus kita terapkan untuk mengerem laju pomografi dan pornoaksi? Di samping membangun kesadaran masyarakat, instrumen yang harus segera diwujudkan oleh pemerintah adalah lahirnya undang-undang anti pornografi. Hal ini senada degan pendapat Ade Armando yang menyatakan bahwa pornografi marak karena tak ada ketegasan hukum.

\section{Pandangan Filsafat Sosial}

Pada bagian ini penyaji mencoba untuk mengkaji realitas "pornografi dan pormoaksi" dari kacamata filsafat sosial. Menurut Soetandyo Wignjosoebroto, filsafat sosial adalah "seluruh koleksi buah gagasan - sebagai hasil renungan reflektif para cerdik cendekia - mengenai tertib sosial kehidupan manusia". Selanjutnya ia mengatakan, apapun yag dipikirkan dan apapun pula yang dihasilkan sebagai simpulan-simpulannya, wacana-wacana dalam filsafat sosial selalu mengandalkan rasionalitas dalam segenap argumen-argumen. Argumen pembenar berlangsung melalui pemikiran deduktif, berawal dari premis-premis paradigmatik yang akan didayagunakan sebagai pembenar hasil simpulan. Adapun yang dimaksud dengan 
premis-premis paradigmatik ini ialah asas-asas paling dasar mengenai suatu kebenaran, nota bene suatu kebenaran yang dipercayai sebagai kebenaran sejati, yang oleh sebab itu idea kebenarannya tidak perlu dijelas-jelaskan lagi karena telah jelas dengan sendirinya ${ }^{5}$.

Untuk itu marilah kita melihatnya dari perspektif dua paradigma, yakni Aristotelian dan Galilean. Dalam filsafat sosial kedua paradigma ini dikatakan berseberangan dalam menatap tatanan sosial (society).Paradigma Aristotelian bertolak dari anggapan aksiomatik bahwa seluruh kenyataan alam semesta ini pada hakikatnya adalah suatu totalitas kodrati yang telah tercipta secara final dalam bentuknya yang sempurna sejak awal mulanya. Nama Gotfried Wilhelm Leibniz (1646-1716) yang disebut sebagai salah seorang representasi paham Aristotelian menyatakan bahwa alam semesta ini pada hakikatnya adalah suatu tertib berkeselarasan yang telah terwujud secara pasti sejak awal mulanya. Inilah yang disebut a pre-established harmounius order. Leibnizbertolakdari keyakinan bahwa Tuhan Mahakuasa dan Mahasempurna itu ada, dan Dialah pencipta semesta ini. Penciptaan tentulah didasari oleh suatu intensi, maksud atau alasan yang mengisyaratkan adanya tujuan yang final (causa finalis) ${ }^{6}$

Dalam kaitan ini Scott Gordon mengilustrasikan keselarasan itu sebagai sebuah orkestra, sebagaimana penjelasannya :

"Sekian banyak pemusik (ialah satuan-satuan yang oleh Leibnizdisebut monad yang independen) telah memainkan bagian masing-masing yang sekalipun secara mandiri namun secara total lalu menjadi berkeselarasan. Dipahamkan bahwa keselarasan itu terwujud tidak karena adanya poses sebab-akibat, dalam arti bahwa permainan pemain yang satu merupakan kausa/sebab dikerjakannya permainan oleh pemain yang lain. Keselarasan itu terwujud tak lain karena adanya partitur yang telah ada dan tercipta serta ditetapkan sejak awal mulanya. Partitur itu telah hadir sebagai bagian yang inheren di dalam setiap satuan (pemain) yang ada di dalam totalitas sistem (orkestra)"'

Lain halnya dengan paradigma Galilean yang bertolak dari anggapan aksionatik yang berbeda dengan paham paradigmatik Aristotelian. Paradigma Galilean menyatakan :

"Bahwa seluruh alam semesta ini pada hakikatnya adalah suatu himpunan fragmen yang berhubung-hubungan secara interaktif dalam suatu jaringan kausalitas 
yang berlangsung tanpa henti dan tanpa mengenal titik henti, di tengah alam objektif (yang karena itu tunduk kepada imperativa alami yang berlaku universal serta berada di luar rencana dan kehendak siapapun). Kecuali objektif, hubungan antar fragmen (yangkelak disebut variabel) itu berlangsung di ranah yang indrawi, dan yang karena itu pula selalu dapat disimak sebagai sesuatu yang faktual dan aktual. Hubungan kausal antar variabel itu berlangsung secara mekanistik dan dapat direproduksi, dan oleh sebab itu pula setiap kejadian atau terjadinya peristiwa selalu dapat saja diprakirakan atau bahkan diramalkan"s

Apabila kita kaitkan kedua paradigma di atas dengan maraknya pornografi dan pornoaksi dewasa ini jelas telah merusak tatanan sosial yang sudah sempurna (perfect order) dan sudah dianggap final. Dengan demikian jika dilihat dari kacamata paradigma yang pertama yaitu Aristotelian, seharusnya Inul tidak mempertontonkan goyang ngebor yang erotis yang merusak tatanan moral dan mengundang disharmoni kehidupan masyarakat. Disharmoni inilah yang dianggap berseberangan dengan tujuan penciptaan alam semesta oleh Tuhan yaitu keharmonisan, keselarasan dan kesempumaan. Namun demikian menurut paradigma Galilean, terjadinya pornografi dan pornoaksi bukanlah tanpa sebab karena dalam hal ini ada hubungan kausalitas diantara variabel-variabel yang saling terkait. Justru karena itu apabila kita hubungkan dengan kasus Inul, ia tidak sendirian, akan tetapi ada variabel lain yang ikut mendukung, antara lain faktor komunitas yang mempunyai sikap permisif terhadap moral dan dukungan media massa yang eksploitatif demi kepentingan bisnis semata.

Selanjutnya kausalitas Galilean di atas, bisa diperjelas dengan tesis Brain Fay, yang menyatakan, "apakah masyarakat atau kebudayaan yang membentuk kita sebagaimana adanya?" Dalam hubungan dengan masalah kontekstual, tesis ini bisa berbunyi, "apakah masyarakat atau kebudayaan yang membentuk perilaku pornografi dan pornoaksi di kalangan kita?” Atau sebaliknya, apakah kita sendiri yang menciptakan budaya pornografi dan pornoaksi di kalangan kita?"

Jawaban yang benar menurut hemat Fay, adalah menolak dikotomi keliru yang terdapat di dalam pertanyaan itu. Karena itu, jawaban yang tepat adalah "keduanya". Kita menciptakan kebudayaan dan masyarakat kita, dan pada gilirannya kebudayaan dan masyarakat itu membentuk kita. ${ }^{9}$ Nah sampai disini bisa kita simpulkan bahwa ada hubungan kausalitas antar variabel, di mana budaya pornografi 
dan pornoaksi bisa mempengaruhi perilaku kita, sebaliknya kita sendiri bisa menciptakan budaya pornografi dan pornoaksi.

\section{Pandangan Islam}

Islam sebagai agama yang sempurna (kaaffah), rahmat bagi sekalian alam, sumber kebenaran dan kebaikan yang memberikan petunjuk kepada manusia untuk memperoleh jalan hidup di dunia dan akhirat, tentu mempunyai sikap tegas terhadap dinamika budaya umat manusia ${ }^{10}$ Dinamika yang dikehendaki Islam adalah dinamika yang positif, yang bermanfaat, tanpa menimbulkan malapetaka dan aniaya, yaitu budaya yang bermakna adab dan peradaban" Sekedar contoh dapat dikutipkan alQuran (3:112) yang artinya : "Kehinaan menimpa mereka di mana saja mereka berada, kecuali jika memegang tali Allah dan memegang tali sesama manusia". Ini berarti, agar manusia tidak ditimpa kehinaan, harus senantiasa berusaha mewujudkan dan menata peradaban dan kebudayaan lahir batinnya, hubungannya dengan Allah dan dengan sesama manusia serta alam sekitar secara harmonis. Hal ini sesuaidengan arti firman Allah : "Wahai orang-orang yang beriman, rukuklah, sujudlah dan sembahlah oleh kamu sekalian, Tuhanmu, dan lakukanlah perbuatanperbuatan yang baik, supaya kamu terpelihara" (al-Quran, 22:27)

Ruku' -sujud dan menyembah Allah adalah ekspresi budaya spiritual, melakukan perbuatan-perbuatan yang baik, mengacu kepada aktivitas manusia dalam hubungannya dengan sesama dan alam sekitar, melahirkan peradaban dan kebudayaan material yang baik ${ }^{12}$

Dalam ayat yang lain Allah menegaskan : "Kamu adalah umat yang terbaik yang dilahirkan untuk manusia, menyuruh kepada yang ma'ruf (perbuatan baik) dan mencegah dari munkar (kejahatan) dan beriman kepada Allah" (al-Quran, 3:110). Dari ayat ini jelas terdapat dua kecendrungan budaya manusia, yaitu budaya yang baik dan budaya yang buruk. Al-Quran hanya menghendaki supaya manusia melahirkan budaya-budaya yang baik saja, yang bermanfaat bagi kebahagiaan hidupnya di dunia dan di akhirat, yaitu budaya yang tidak merusak akhlak, alam dan lingkungan ${ }^{13}$

Manusia dalam melakukan tugas kekhalifahannya guna memakmurkan bumi, apapun bentuk dan macamnya, selalu dikontrol atau diawasi oleh Allah, sebagaimana firman-Nya : "Dan katakanlah (wahai Muhammad) hendaklah kamu berkarya, 
Allah, rasul-Nya dan orang-orang yang beriman akan melihat karyamu itu. Nanti kamu akan dikembalikan kepada-Nya, yang Maha Mengetahui yang ghaib dan yang lahir, lalu diberitakan-Nya padamu segala karyamu... Dan Dia bersama kamu di mana saja kamu berada dan Allah Maha Melihat apa saja yang kamu kerjakan", (al-Quran, 9:105; 5.7:4).

Lebih jauh Allah memberi dorongan agar manusia terus berkarya, disertai dengan peringatan, sebagaimana firman-Nya : "Hai orang-orang yang beriman, bertakwalah kepada Allah. Dan hendaknya setiap diri memperhatikan apa yang telah diperbuatnya untuk hari esok. Bertakwalah kepada Allah, sesungguhnya Allah Maha Mengetahui apa yang kamu lakukan. Dan hari esok lebih baik bagimu dari hari kini"(al-Quran, 59:18; 57:4)

Sampai di sini dapat disimpulkan bahwa dalam menghadapi dinamika budaya, al-Quran memberikan konsep peringatan, petunjuk, pengarahan, kontrol dan pengawasan. Hal ini dimaksudkan agar ajaran Islam yang sempurna dan baik itu: mengekspresikan budaya atau peradaban yang tidak bertentangan dengan esensi kesempurnaan itu sendiri...Dengan ekspresi budaya yang baik dan sempurna itu pula akan terbukti secara empiris teori yang menyatakan, bahwa Islam adalah rahmatan lil 'alamin't

Dalam kaitan dengan dinamika budaya ini Harun Nasution menyatakan :

"Kalau kebudayaan timbul sebagai hasil dari interaksi antara pemikiran akal dan kenyataan dalam masyarakat; maka dengan sendirinya kebudayaan juga bersifat dinamis. Dengan demikian tidak mengherankan kalau antara agama dan perkembangan kebudayaan selalu terdapat ketidakharmonisan. Selalu dijumpai bahwa dalam masyarakat yang kuat berpegang pada dogma againa, kebudayaan sulit dapat berkembang dengan baik. Dinamika kebudayaan diikat oleh keyakinankeyakinan dan tradisi lama dalam agama"'s .

Maksud pernyataan Nasution di atas bahwa dinamika kebudayaan merupakan hasil interaksi atau pengaruh manusia terhadap realitas sosial. Kemajuan budaya sebagai sebuah realitas sosial sangat tergantung sejauh mana manusia berpegang teguh pada dogma agama. Semakin ketat dogma agama dipegangi (submissive), maka berkecendrungan semakin lamban perkembangan suatu budaya. Sebaliknya, semakin longgar memegangi dogma (permissive), maka berkecendrungan budaya akan semakin cepat perkembangannya. Tesis kedekatan pengaruh ini sejalan dengan

Ulul Albab, Vol. 4 No. 1, 2003 
pendapat Nurcholish Madjid yang menyatakan : "Sebagian besar budaya didasarkan pada agama; tidak pernah terjadi sebaliknya. Oleh karena itu, agama adalah primer, dan budaya adalah sekunder. Budaya bisa merupakan ekspresi hidup keagamaan, karena ia subordinal terhadap agama, dan tidak pernah sebaliknya"'6Karena itu saran Harun agar budaya itu berkembang, manusia selaku subjek agama, harus berani menggunakan akal pikiran secara kritis dan terbuka sebagaimana telah banyak dipraktikkan oleh para ilmuwan di abad klasik peradaban Islam. Tentu saja daya kritis dan keterbukaan itu sepanjang dalam koridor nilai-nilai Islam.

\section{Kesimpulan}

Bertolak dari uraian di atas, dapat disimpulkan bahwa budaya poinografi dan pornoaksiadalah merupakan realitas sosial yang ditumbuhsuburkan oleh interaksi antar variabel, antara lain media massa, kepentingan bisnis, gaya hidup hedonistik sekularistik, dan sebagainya. Dalam konteks keindonesiaan, di mana mayoritas penduduknya menganut ajaran Islam, budaya seperti itu (apapun bentuknya )jelas sangat menistakan. Karena dianggap kontra produktif dengan keyakinan masyarakat dan telah mengarah pada demoralisasi, sangatlah wajar bila banyak mendapat respon negatif dari banyak kalangan.

Dalam menyikapi masalah realitas ini, filsafat sosial hanya sebatas menyatakan bahwa pornografi dan pornoaksi bisa melahirkan disharmoni di tengah keselarasan alam semesta yang sudah dianggap final (paradigma Aristotelian). Di samping paradigma Galilean yang didukung tesis Brian Fay, yang menyatakan bahwa budaya ini terjadi karena hubungan kausalitas antara masyarakat dan budaya itu sendiri.

Dalam hal ini tampaknya Islam bersikap kompromistis, karena pandangannya merupakan sintesa dari pernyataan kedua paradigma di atas. Islam menegaskan bahwa budaya pornografi dan pornoaksi pasti akan mengganggu tatanan sosial, dan budaya itu terjadi karena ada interaksi dengan masyarakat di mana budaya itu hidup. Hanya saja satu sisi kelebihan dalam Islam, di samping ia mendorong kemajuan budaya, sekaligus memberikan konsepperingatan, petunjuk, pengarahan, kontrol dan pengawasan terhadap pelakubudaya, yang kesemuanya ini tidak ditemui dalam ajaran yang lain mana pun. Wallahu 'alam bi al-sawab. 


\section{Endnotes}

Tabloid Republika Dialog Jumat, edisi Jum'at, 23 Mei 2003, hlm. 3

2. Ibid.

3 Republika, edisi 25 Mei 2003, hlm. 5

4. Tanggapan para tokoh ini dirangkum dari Tabloid Dialog Jumat Republika edisi 23 Mei 2003 dan Harian Republika, edisi 3 Mei 2003

5 Soetandyo Wignjosoebroto, Bahan Kuliah Filsafat Sosial Program Doktor Program Pascasarjana IAIN Sunan Ampel Surabaya, 2003, Surabaya, 2003, hlm.1

6 Ibid

7 Scott Gordon, The History and Philosophy of Social Science, New York, Routledge; 1991, hlm.214-215

- Sutandyo Wignjosoebroto, Op.Cit.

9. . Brian Fay, Filsafat Ilmu Sosial Kontemporer (alih bahasa : M. Muhith), Penerbit Jendela dan Tadarus, 2002, hlm. 99

10. Yang dimaksudkan dengan budaya di sini penulis mengutip pendapat Effat al-Syarqawi dalam Atang Abd. Hakim dan Jaih Mubarok, Metodologi Studi Islam , Bandung, Penerbit PT Rosda Karya, 1999, hlm. 30 yang membedakannya dengan peradaban. Menurut al-Syarqawi, kebudayaan adalah apa yang kita rindukan (ideal), sedangkan peradaban adalah apa yang kita pergunakan.(real). Dengan kata lain,jelas al-Syarqawi, kebudayaan terefleksi dalam seni, sastra, religi, dan moral; sedangkan peradaban terefleksi dalam politik, ekonomi, dan teknologi.

" Burhanuddin Daya, "Al-Qur'an dan Pembinaan Budaya (Perspektif Agamis)", dalam Abdul Basir Solissa (ed), Alquran \& Pembinaan Budaya (Dialog dan Transformasi), Yogyakarta, Lembaga Studi Filsafat Islam (LESFI), 1993, hlm. 49

12 Ibid.

13 Ibid., hlm.50

14 Ibid., hlm.51

15 Harun Nasution, "Tinjauan Filosofis tentang Pembentukan Kebudayaan dalam Islam", dalam Abdul Basir Solissa (ed), Alquran \&Pembinaan Budaya (Dialog dan Transformasi), Yogyakarta, Lembaga Studi Filsafat Islam (LESFI), 1993, hlm. 16

16 Yustion dkk, (Dewan Redaksi), Islam dan Kebudayaan Indonesia : Dulu, Kini, dan Esok, Jakarta, Yayasan Festival Istiqlal, 1993, hlm.172-3)

Ulul Albab, Vol. 4 No. 1, 2003 


\section{Bibliography}

Daya, Burhanuddin, "Al-Quran dan Pembinaan Budaya(Perspektif Agamis)" dalam Abdul Basir Solissa (ed), Alquran \& Pembinaan Budaya (Dialog dan Transformasi), Lembaga Studi Filsafat Islam (LESFI), Yogyakarta, 1993

Fay, Brain, Filsafat Ilmu Sosial Kontemporer (alih bahasa : M.Muhith), Penerbit Jendela dan Tadarus, Yogyakarta - Pasuruan, 2002

Gordon, Scott, The History dan Philosophy of Social Science, Routledge, New York, 1991

Hakim, Atang Abd dan Jaih Mubarok, Metodologi Studi Islam, Penerbit PT Rosda Karya, Bandung, 1999

Harian Republika, edisi 3 Mei dan 25 Mei 2003-05-29

Nasution, Harun, "Tinjauan Filosofis tentang Pembentukan Kebudayaan dalam Islam", dalam Abdul Basir Solissa (ed), Alquran \& Pembinaan Budaya (Dialog dan Tarnsformasi), Lembaga Studi Filsafat Islam (LESFI), Yogyakarta, 1993

Solissa, Abd. Basir (ed), Alquran \& Pembinaan Budaya (Dialog danTarnsformasi), Lembaga Studi Filsafat Islam (LESFI), Yogyakarta, 1993

Tabloid Republika Dialog Jumat, edisi Jum'at 23 Mei 2003

Wignjosoebroto, Soetandyo, Bahan Kuliah Filsafat Sosial Program Doktor Program Pascasarjana IAIN Sunan Ampel Surabaya 2003, Surabaya, 2003

Yustion dkk., (Dewan Redaksi), Islam dan Kebudayaan Indonesia : Dulu, Kini dan Esok, Yayasan Festival Istiqlal, Jakarta, 1993 